\title{
BMJ Open Health-related preferences of older patients with multimorbidity: an evidence map
}

\author{
Ana Isabel Gonzalez (1) ,1,2 Christine Schmucker, ${ }^{3}$ Julia Nothacker, ${ }^{3}$ \\ Edith Motschall, ${ }^{4}$ Truc Sophia Nguyen, ${ }^{1}$ Maria-Sophie Brueckle, ${ }^{1}$ Jeanet Blom, ${ }^{5}$ \\ Marjan van den Akker, ${ }^{1,6}$ Kristian Röttger, ${ }^{7}$ Odette Wegwarth (D) , \\ Tammy Hoffmann, ${ }^{9}$ Sharon E Straus, ${ }^{10}$ Ferdinand M Gerlach, ${ }^{1}$ Joerg J Meerpohl, ${ }^{3}$ \\ Christiane Muth ${ }^{1}$
}

To cite: Gonzalez Al, Schmucker C, Nothacker J, et al. Health-related preferences of older patients with multimorbidity: an evidence map. BMJ Open 2019;9:e034485. doi:10.1136/ bmjopen-2019-034485

- Prepublication history and additional material for this paper are available online. To view these files, please visit the journal online (http://dx.doi. org/10.1136/bmjopen-2019034485).

AIG and CS contributed equally. JJM and CM contributed equally.

Presented at 53rd Congress for General Practice and Family Medicine, Deutsche Gesellschaft für Allgemeinmedizin und Familienmedizin (DEGAM), Erlangen, 12. - 14.09.2019

Received 22 September 2019 Revised 23 October 2019 Accepted 01 November 2019

D Check for updates

(c) Author(s) (or their employer(s)) 2019. Re-use permitted under CC BY-NC. No commercial re-use. See rights and permissions. Published by BMJ.

For numbered affiliations see end of article.

Correspondence to Dr Christiane Muth; muth@allgemeinmedizin.unifrankfurt.de

\section{ABSTRACT}

Objectives To systematically identify knowledge clusters and research gaps in the health-related preferences of older patients with multimorbidity by mapping current evidence.

Design Evidence map (systematic review variant). Data sources MEDLINE, EMBASE, PsycINFO, PSYNDEX, CINAHL and Science Citation Index/Social Science Citation Index/-Expanded from inception to April 2018.

Study selection Studies reporting primary research on health-related preferences of older patients (mean age $\geq 60$ years) with multimorbidity ( $\geq 2$ chronic/acute conditions).

Data extraction Two independent reviewers assessed studies for eligibility, extracted data and clustered the studies using MAXQDA-18 content analysis software.

Results The 152 included studies (62\% from North America, 28\% from Europe) comprised 57093 patients overall (range 9-9105). All used an observational design except for one interventional study: 63 (41\%) were qualitative (59 cross-sectional, 4 longitudinal), 85 (57\%) quantitative (63 cross-sectional, 22 longitudinal) and $3(2 \%)$ used mixed methods. The setting was specialised care in 85 $(56 \%)$ and primary care in $54(36 \%)$ studies. We identified seven clusters of studies on preferences: end-of-life care $(n=51,34 \%)$, self-management $(n=34,22 \%)$, treatment $(\mathrm{n}=32,21 \%)$, involvement in shared decision making $(n=25,17 \%)$, health outcome prioritisation/goal setting $(n=19,13 \%)$, healthcare service $(n=12,8 \%)$ and screening/ diagnostic testing $(n=1,1 \%)$. Terminology (eg, preferences, views and perspectives) and concepts (eg, trade-offs, decision regret, goal setting) used to describe health-related preferences varied substantially between studies.

Conclusion Our study provides the first evidence map on the preferences of older patients with multimorbidity. Included studies were mostly conducted in developed countries and covered a broad range of issues. Evidence on patient preferences concerning decision-making on screening and diagnostic testing was scarce. Differences in employed terminology, decision-making components and concepts, as well as the sparsity of intervention studies, are challenges for future research into evidencebased decision support seeking to elicit the preferences of older patients with multimorbidity and help them construct preferences.
Strengths and limitations of this study

- This evidence map presents a systematic overview of studies addressing a variety of health-related preferences in older patients with multimorbidity.

- We identified clusters of studies on, for example, health outcome prioritisation and end-of-life care preferences; few studies addressed preferencesensitive decisions on screening and diagnostic testing.

- The terminology and concepts used to address health-related preferences varied considerably in the included studies, highlighting a need for more standardisation to improve further research.

Trial registration number Open Science Framework (OSF): DOI 10.17605/OSF.IO/MCRWQ.

\section{INTRODUCTION}

Multimorbidity, defined as the co-occurrence of multiple medical conditions in a person, ${ }^{1}$ is a growing public health concern that affects approximately two-thirds of people over the age of 60 years. ${ }^{2}{ }^{3}$ Patients with multimorbidity generally experience a higher burden of disease, physical disabilities, adverse drug reactions, more frequent hospital admissions, reduced quality of life and increased mortality compared with those with a single condition. ${ }^{45}$ As patients face new and growing demands to organise and coordinate their own care to comply with treatment regimens, multiple chronic conditions are often associated with high treatment burden in addition to the burden of the diseases themselves. ${ }^{6}$ If patients are overwhelmed by the burden, they limit their compliance to their preferred tasks. ${ }^{7}$ Moreover, the care of patients with multimorbidity is challenging, as treatments for one condition may adversely affect another. ${ }^{8}$ Robust evidence supporting 
decision-making in these patients is scarce, ${ }^{2}$ and the use of multiple disease-based guidelines is inappropriate, as they do not adequately consider potentially interacting conditions and treatments. ${ }^{9} 10$

The delivery of healthcare in patients with multimorbidity requires a patient-centred approach, that is 'respectful of and responsive to individual patient preferences, needs and values, and ensuring that patient values guide all clinical decisions' ${ }^{11}$ The 'Ariadne principles' ${ }^{12}$ stress the importance of physicians and patients sharing realistic treatment goals, and of individualising management and follow-up by taking patients' preferences into consideration when making clinical decisions. Recent clinical guidelines on multimorbidity have embraced this approach and emphasise the incorporation of patients' preferences in clinical decision-making, for example in the selection of appropriate self-management activities and treatment options, as well as in the prioritisation of health outcomes. ${ }^{13}$ Similarly, the consideration of patients' views in the form of patient-reported experiences and care outcomes have been recognised as critical to the achievement of high-performing health systems that are responsive to the needs of people with multimorbidity. ${ }^{14}$

It remains unclear how health-related preferences can be elicited from older patients with multimorbidity, as patients may be unfamiliar with the decision elements. ${ }^{15}$ Moreover, concerns have been raised that patients are often provided with too little information about the benefits and harms of a treatment, ${ }^{16} 17$ may find it difficult to prioritise health outcomes and make trade-offs, and in consequence, may refrain from participating in the decision making process. ${ }^{18}$ As evidence maps allow a systematic approach to be used to collate evidence on a broad topic, we used this emerging method to map the health-related preferences of older patients with multimorbidity. ${ }^{19}$ In particular, we aimed to (1) systematically identify and describe key characteristics of research on health-related preferences of older patients with multimorbidity, (2) display the landscape of existing research in visual formats, (3) identify evidence clusters to guide any subsequent knowledge synthesis (systematic reviews and meta-analysis) and (4) identify evidence gaps and encourage relevant stakeholders and funding agencies to prioritise these in future research.

\section{METHODS}

\section{Reporting protocol and guideline}

We described the methods in a study protocol ${ }^{20}$ that has since been subject to no amendments, registered the evidence map in Open Science Framework (OSF, DOI 10.17605/OSF.IO/MCRWQ) and adhered to the Preferred Reporting Items for Systematic Reviews and Meta-Analyses Extension for Scoping Reviews checklist $^{21}$ where possible (see online supplementary table S1).

\section{Systematic literature search}

We searched the electronic databases MEDLINE and EMBASE (via Wolters Kluwer's search interface Ovid), PsycINFO, PSYNDEX and CINAHL (via EBSCOhost) and Social Science Citation Index and Science Citation Index Expanded (via Web of Science from Clarivate Analytics) from inception until April 2018. In our search, we combined medical subject headings with keywords covering old age, multimorbidity, polypharmacy and search terms related to patient preferences. The search strategy was adapted to suit the database under review (see online supplementary table S2 on Search strategy in MEDLINE-Ovid).

Based on the 32 most relevant studies identified in our initial search (ie, when keywords provided by the author contained the terms 'multimorbidity' and 'patient preferences' or 'patient priorities' and/or described a specific method for eliciting patients' preferences, such as 'conjoint analysis'), we conducted a cited reference search (forward citation tracking) using the Web of Science Core Collection. We also checked the reference lists of included studies, the reference lists of systematic reviews on related topics for further studies (hand search) and contacted the authors of conference proceedings that had not published a full set of results. We searched for ongoing trials in the Register for Clinical Trials ${ }^{22}$ and the WHO International Clinical Trials Registry. ${ }^{23}$

\section{Inclusion and exclusion criteria}

We included qualitative and quantitative studies involving older patients of 60 years and older with multimorbidity (two or more simultaneous chronic or acute conditions ${ }^{1}$ ) that addressed health-related patient preferences. We also included studies involving older patients with chronic conditions that are frequently associated with multimorbidity, even if they were not reported in detail (chronic heart failure, chronic obstructive pulmonary disease (COPD), chronic kidney disease, advanced cancer and frailty). ${ }^{24-26}$

We excluded studies investigating preferences relating to interventions of limited availability or whose legal status was unclear (eg, euthanasia, which is not legal or available in most countries), studies addressing the preferences of caregivers, family or medical and/or other professionals as well as case reports, narrative reviews and editorials. We did not apply any restrictions to the geographical location of the study or language of publication.

\section{Study selection}

Two reviewers (AIG and JN) screened the titles and abstracts of all references identified by electronic searches. Before screening, stepwise calibration was performed on a sample of 50 studies, with the aim of achieving $80 \%$ agreement between the two reviewers. ${ }^{20}$ If $80 \%$ agreement had not been reached, our inclusion and exclusion criteria would have been refined to reach this cut-off. The new criteria would then have required further calibration using a new sample of 50 studies until the threshold was 
reached. We also obtained full texts of potentially relevant articles, and two reviewers (AIG, JN or CS) independently assessed these for inclusion. Conflicts were resolved by discussion among reviewers.

\section{Mapping the evidence \\ Data extraction}

Following the calibration of five full text articles, two reviewers (AIG, JN or CS) independently extracted data on (1) study characteristics including study design (observational (qualitative, quantitative or mixedmethods, cross-sectional or longitudinal) and interventional), geographical area, study setting (eg, primary care), sample size, (2) study aim, (3) patient population (eg, definition of multimorbidity, age, sex) and (4) characteristics of preferences, such as methods used to elucidate patients' preferences, and definition of preferences according to the authors.

\section{Types of preference}

We conducted qualitative relational content analysis ${ }^{27}$ to derive overarching themes. The analysis was based on coding by two independent reviewers (AIG, JN or CS) using MAXQDA-18, which were further scrutinised by $\mathrm{CM}, \mathrm{JWB}, \mathrm{MvdA}$, TSN and MSB. ${ }^{20}$ The initial step was to scrutinise title and abstract (focusing on the study aim) of the included studies to gain a general understanding of what the study was about. The full text was then read and re-read and codes assigned (eg, resuscitation preferences ${ }^{28}$, which were later grouped according to overarching themes (eg, life-sustaining treatment preferences). ${ }^{27} 28$ Reviewers' categorisation of preference types was partly based on a previous classification (ie, end-of-life preferences, prioritisation of health problems, prioritisation of medication, preferences regarding the role played in decision-making, preferences in surgical treatment methods, prioritisation of treatment goals, determinants of preference, changes in preferences and preferences concerning the organisation of healthcare) obtained from a pilot study (published elsewhere) of the evidence map.

\section{Mapping}

We tabulated the identified studies, summarised study and patient characteristics, as well as study publications per year, and used bubble plots to display evidence clusters in terms of preference type and study characteristics.

\section{Patient and public involvement}

A patient representative (KR) from the Federal Joint Committee 'Gemeinsamer Bundesausschuss (G-BA)' was involved in the conception and development of the evidence map, in the interpretation of the findings, and in writing the manuscript. KR has considerable expertise in evidence-based medicine in a healthcare context, and an understanding of the pivotal role of patients' preferences in the provision of effective healthcare.

\section{RESULTS}

\section{Literature search and selection process}

Among the 9145 unique screened references, 152 studies (comprising over 57000 patients) were included in the evidence map. As $80 \%$ agreement between the two reviewers was achieved in the first calibration exercise, inclusion and exclusion criteria remained unchanged. We contacted 48 authors of conference papers (13\% answered) and included one further study that had already been identified in our electronic search (figure 1). Online supplementary tables S3a-3f show key characteristics of the included studies. Online supplementary table S4 presents excluded studies and reasons for exclusion.

\section{Key characteristics of the included studies and participants}

Of the included studies, all but one were observational $(151 / 152)$, and nearly all were conducted in developed countries $(147 / 152)$ (table 1, online supplementary tables S3a-S3f) and published in 2007 or thereafter $(128 / 152)$ (see online supplementary figure S1). All studies were written in English.

The sample size ranged from 9 to 9105 patients and captured both sexes ( $51 \%$ female). The mean age of participants ranged from 60 to 85 years. Eight studies ${ }^{29-36}$ included different age groups but only data from patients aged 60 years and older were included in the evidence map. Three studies ${ }^{36-38}$ provided no age estimate but were included because they clarified that they had only included older patients. In 87 of the included studies, patients with multimorbidity (no index disease defined) or comorbidity (index disease defined plus at least one other associated condition) were investigated, and in the remaining 65 studies, patients with conditions known to be highly associated with multimorbidity were included.

\section{Types of preference and evidence clusters}

Content analysis ${ }^{27}$ enabled us to identify seven major types of preference (table 2). We assigned 130 studies $(85 \%)$ to one of these types of preference and $22(15$ $\%$ ) studies ${ }^{3739-57}$ to two types of preference. Terminology (eg, preferences, views and perspectives) and concepts (eg, trade-offs, decision regret and goal setting) varied substantially among studies.

\section{End-of-life care preferences}

The largest evidence cluster comprised the 51 studies (34\%) addressing end-of-life care preferences, most of which were in specialised care settings (41/51 studies) (figure 2). Content analysis of this preference revealed that advance care planning, ${ }^{42}$ in which multimorbid patients with advanced chronic diseases were asked how they would like to be cared for in the final months of their lives, was the main theme (table 2). The most common theme within this cluster concerned preferences for specific life-sustaining treatments $(29 / 51),{ }^{28} 32-343658-81$ such as cardiopulmonary resuscitation or mechanical ventilation. Additional topics in this cluster addressed 


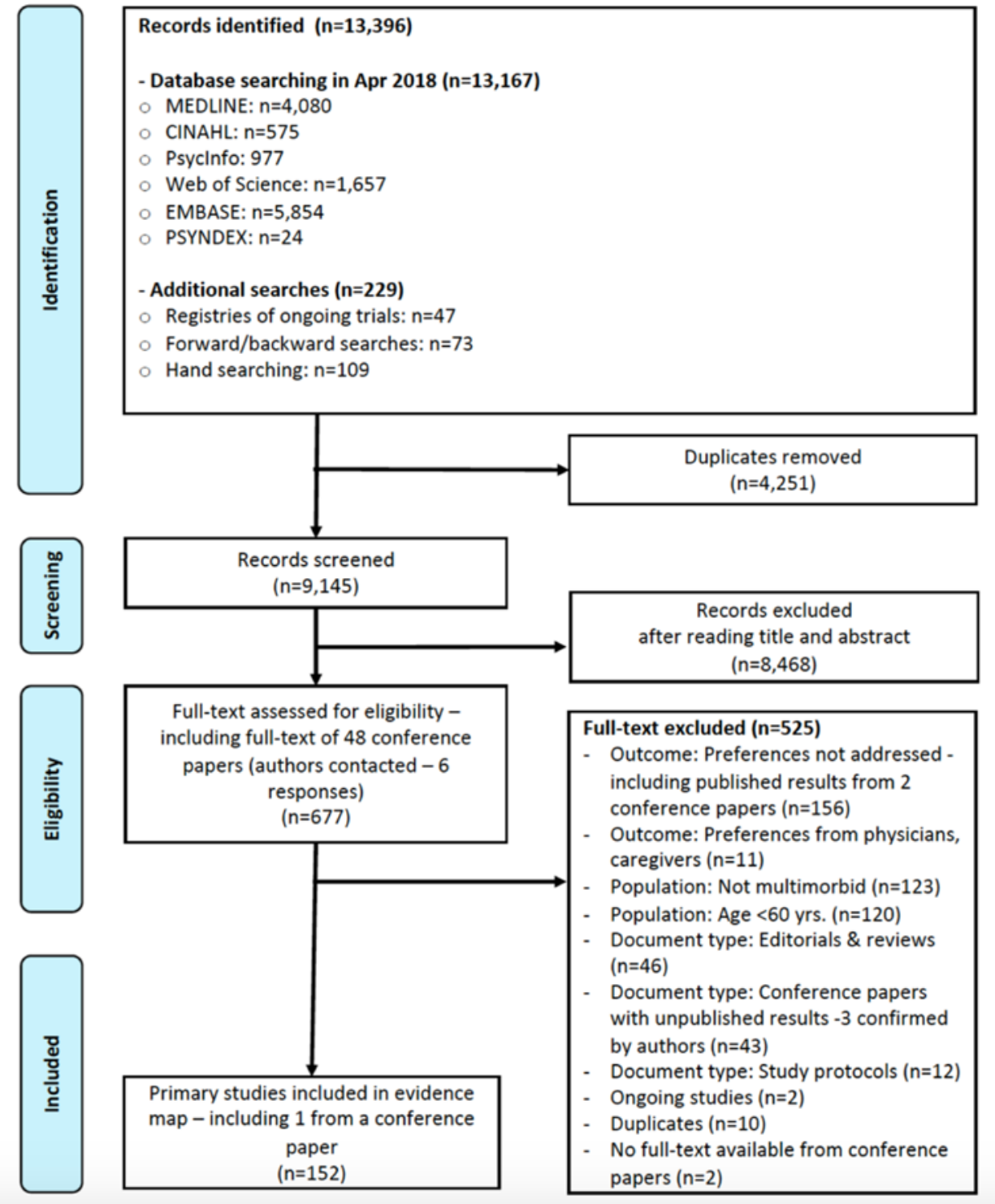

Figure 1 Evidence map Preferred Reporting Items for Systematic Reviews and Meta-Analyses flowchart.

themes such as the preferred place of death (eg, home vs hospice).$^{60}$

\section{Self-management preferences}

The second largest evidence cluster included 34 studies $(22 \%)$ and addressed patients' self-management priorities, defined as activities that an individual undertakes to maintain or reduce the effect of a disease(s) on their health status. ${ }^{82}$ Most studies about self-management preferences were conducted in primary care $(21 / 34)$. The only intervention study in the evidence map (113) used a cluster-randomised design to evaluate whether structured priority-setting consultations led to a sustainable reconciliation of diverging physician-patient views on the importance of health problems. Overall, content analysis of this evidence cluster revealed five key themes: (1) patients' prioritisation of their multiple health problems $(20 / 34),{ }^{30} 45475483-98$ as an example of which patients were asked how they prioritised their osteoarthritis over their other conditions, ${ }^{97}$ (2) patients' preferences regarding self-management of their medications $(8 / 34)^{42} 43475499-102$ and, for instance, its association with treatment adherence $^{42}$ (3) patients' self-care behaviours $(3 / 34)^{44} 55103$ aimed at accomplishing their life goals ${ }^{44}$ (4) characteristics of eHealth support tools $(2 / 34)^{30104}$ to help patients self-manage their multiple health conditions ${ }^{104}$ and (5) changes in patients' choices resulting from changing circumstances $(2 / 34){ }^{29} 30$

\section{Treatment preferences}

Thirty-two studies (22\%) investigated a variety of treatment preferences concerning (1) medication $(13 / 32),{ }^{37} 41-4347495354$ 105-108 perhaps for a specific blood pressure-lowering drug due to its characteristics (eg, effects and dose schedule) ${ }^{106}$ (2) dialysis as a treatment option in end-stage renal disease $(6 / 32),{ }^{48} 109-113$ (3) surgery $(4 / 32),{ }^{114-117}$ such as a decision in favour of implantable cardioverter-defibrillators or joint replacement, (4) chemotherapy $(5 / 32), 3^{35}{ }^{518-120}$ for which studies may have examined preferences in adjuvant cancer 


\begin{tabular}{|c|c|}
\hline Variable & Total-n (\%) \\
\hline \multicolumn{2}{|l|}{ Study characteristics } \\
\hline \multicolumn{2}{|l|}{ Geographical location } \\
\hline North America & $94(62 \%)$ \\
\hline Europe & $43(28 \%)$ \\
\hline Australia and New Zealand & $10(7 \%)$ \\
\hline Asia & $5(3 \%)$ \\
\hline \multicolumn{2}{|l|}{ Setting } \\
\hline Primary care & $54(36 \%)$ \\
\hline Outpatient specialised & $59(39 \%)$ \\
\hline Hospital (inpatient and emergency) & $26(17 \%)$ \\
\hline Nursing homes & $5(3 \%)$ \\
\hline Interdisciplinary & $8(5 \%)$ \\
\hline \multicolumn{2}{|l|}{ Study design/method } \\
\hline Qualitative (observational) & $63(42 \%)$ \\
\hline Cross-sectional (observational) & $59(39 \%)$ \\
\hline Longitudinal (observational) & $4(6 \%)$ \\
\hline Quantitative & $86(57 \%)$ \\
\hline Cross-sectional (observational) & $63(41 \%)$ \\
\hline Longitudinal (observational) & $22(15 \%)$ \\
\hline Interventional & $1(1 \%)$ \\
\hline $\begin{array}{l}\text { Mixed methods (qualitative and } \\
\text { quantitative) }\end{array}$ & $3(2 \%)$ \\
\hline Observational (total) & $151(99 \%)$ \\
\hline Interventional (total) & $1(1 \%)$ \\
\hline Sample size-median (range) & $83(9-9105)$ \\
\hline \multicolumn{2}{|l|}{ Observational } \\
\hline Qualitative & $30(9-160)$ \\
\hline Quantitative & $196(11-9105)$ \\
\hline Mixed methods & $50(32-60)$ \\
\hline Interventional & 317 \\
\hline
\end{tabular}

\section{Patients' characteristics}

\section{Type of condition}

\begin{tabular}{lc}
$\begin{array}{l}\text { Studies describing multimorbid patients* } \\
\text { Studies describing patients with an } \\
\text { index disease and comorbidity }\end{array}$ & $58(38 \%)$ \\
Diabetes & $29(19 \%)$ \\
Hypertension & $7(5 \%)$ \\
Depression/mental illness & $5(3 \%)$ \\
Cardiovascular disease & $4(3 \%)$ \\
Osteoarthritis & $4(3 \%)$ \\
$\quad$ Other & $3(2 \%)$ \\
$\begin{array}{l}\text { Studies describing patients with chronic } \\
\text { conditions often associated with } \\
\text { multimorbidity }\end{array}$ & $65(4 \%)$ \\
$\quad$ Chronic heart failure & \\
Advanced cancer & $10(7 \%)$ \\
\hline
\end{tabular}

Continued
Table 1 Continued

\begin{tabular}{|cc|}
\hline Variable & Total $-\mathbf{n}(\%)$ \\
\hline \multicolumn{1}{c}{ Chronic kidney disease } & $15(10 \%)$ \\
\hline COPD & $4(3 \%)$ \\
Mixed (heart failure, COPD...) & $20(13 \%)$ \\
Age (range) $\dagger$ & $60-85$ \\
Sex (\% female) $\dagger$ & $28905(51 \%)$ \\
\hline
\end{tabular}

*No further details of included conditions were reported in the majority of studies.

†Studies with overlapping population were excluded $(n=10) .3658598384105109149161169$

COPD, chronic obstructive pulmonary disease.

treatments and (5) non-pharmacological/conservative interventions (3/32), ${ }^{121-123}$ such as studies exploring preferences for activity interventions. ${ }^{121}$

\section{Involvement in the shared decision making process}

Twenty-five $(17 \%)$ studies explored how patients preferred to be involved in the shared decision making process. Studies in this cluster investigated preferred (1) patterns of engagement $(21 / 25),{ }^{374146} 48-5257$ 124-133 (2) information $(4 / 25),{ }^{39} 52128134$ (3) communication with providers $(1 / 25)^{40}$ and (4) patient decision aids $(1 / 25){ }^{56}$

\section{Healthcare service preferences}

Twelve studies $(8 \%)$ focused on preferences for certain healthcare services, and specifically (1) preferred care processes $(10 / 12),{ }^{45} 135-143$ such as continuity of care, accessibility and acceptance of the substitution of a physician by nurses and (2) service models (2/12), ${ }^{31} 144$ perhaps asking patients about their preferences regarding Chronic Care Model recommendations. ${ }^{31}$

Health outcome prioritisation and goal setting

Nineteen studies (13\%) investigated health outcome prioritisation and goal setting. These may have been (1) patients' holistic goals for their lives or with respect to their various diseases $(6 / 19),{ }^{44}{ }^{55}$ 145-148 $^{\text {(2) health }}$ outcome prioritisation $(10 / 19)^{53}{ }^{149-157}$ —one study in particular addressed the tools patients preferred to use to prioritise health outcomes ${ }^{151}$ and (3) collaborative goal setting among patients, physicians and caregivers $(3 / 19) .103158159$

Screening and diagnostic tests

One study ${ }^{160}$ investigated cancer screening preferences among patients with multimorbidity.

\section{DISCUSSION AND CONCLUSION}

This work provides a systematic overview of research on health-related preferences of older patients with multimorbidity. 


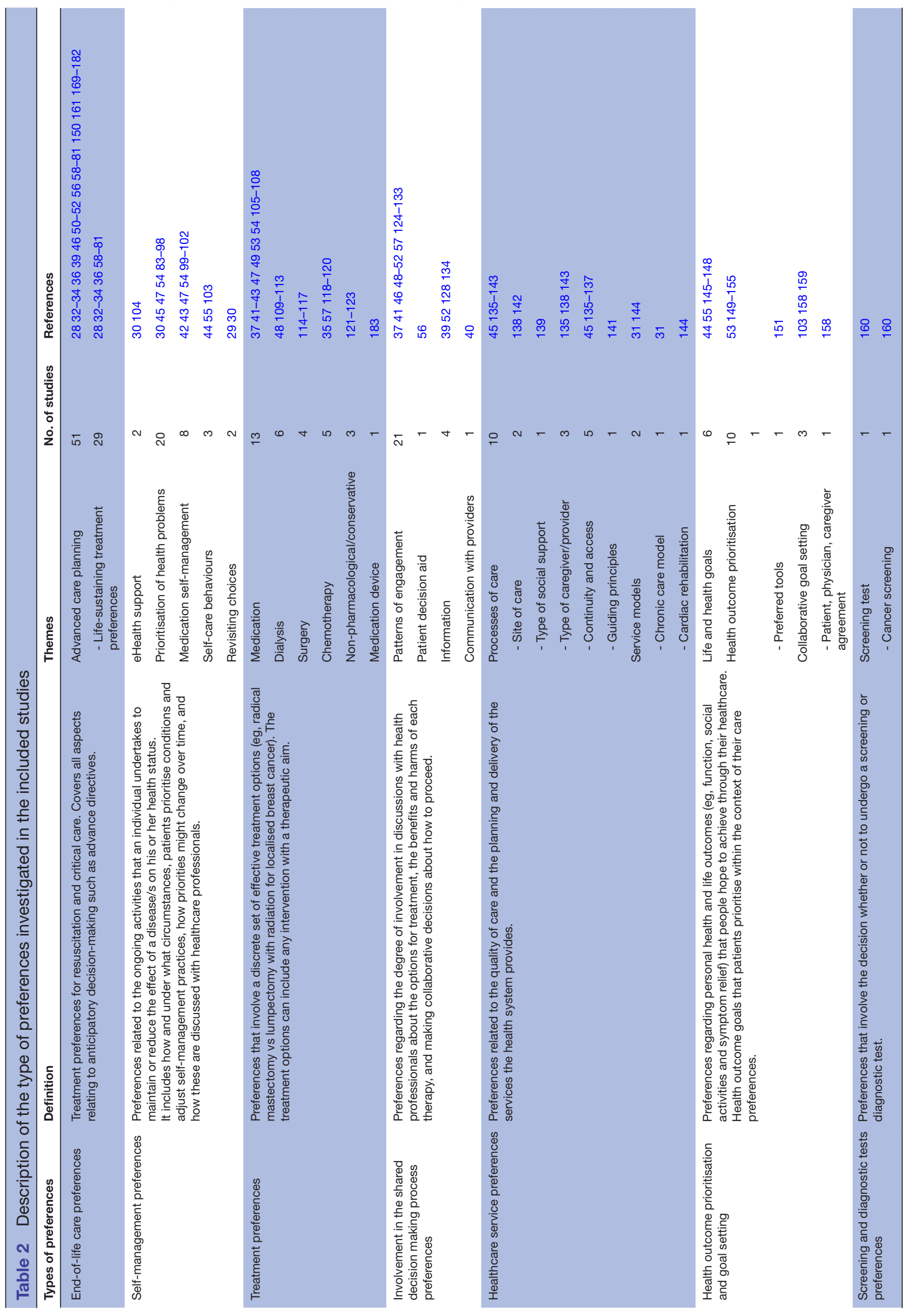

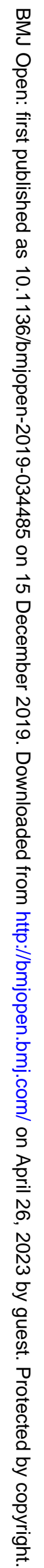




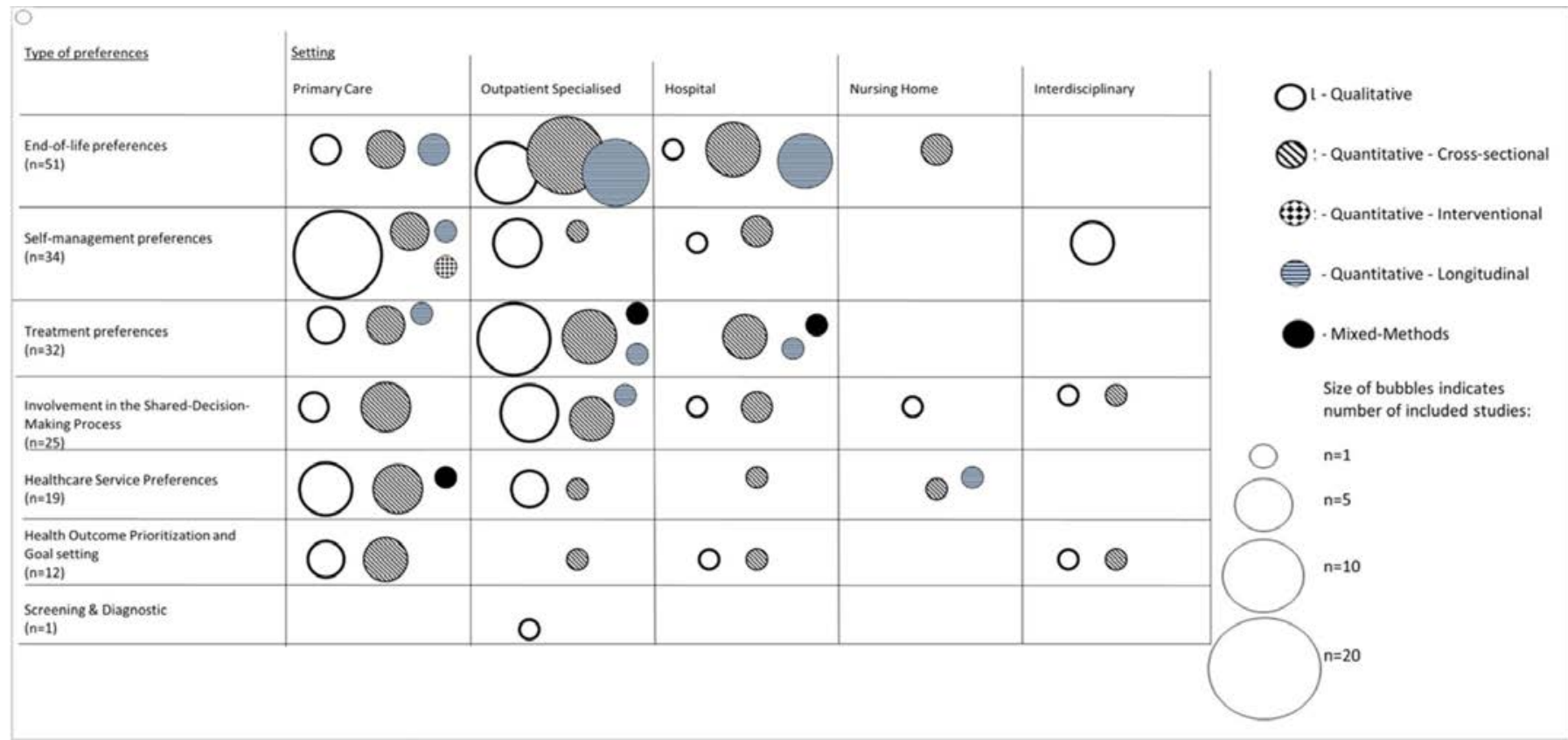

Figure 2 Types of preference by setting and study design. Circle size represents the number of studies; pattern coding represents the study design. *The bubble plot displays more than the total number of included studies $(n=174$ vs $n=152)$ because 22 studies were assigned to two different types of preference.

\section{Evidence clusters}

We identified 152 studies, most of which were published within the last decade and conducted in developed countries. The vast majority of studies included in the evidence map used a qualitative or cross-sectional quantitative design $(126 / 152)$.

Our clustering approach revealed that studies of patient preference focused on seven areas: end-of life care, selfmanagement, treatment, involvement in shared decision making, health outcome prioritisation/goal setting, healthcare service delivery and screening/diagnostic testing. The size of the evidence clusters varied widely (from 1 to 51 studies) and the research objectives and settings differed considerably.

The largest and most homogenous cluster was of end-oflife preferences (51/152 studies) and was largely confined to specialised care $(41 / 51)$. Furthermore, the study objectives revealed one overarching theme (advance care planning) and were relatively uniform compared with the other clusters.

Self-management and treatment preferences were the second (34/51) and third (32/51) largest clusters respectively. Although studies about self-management preferences were relatively homogeneous in terms of study setting (they were mostly conducted in primary care $(21 / 34))$, we found considerable variability in the overarching themes. Treatment preferences were rather heterogeneous, with the cluster containing a variety of settings and themes.

Overall, we identified clusters of evidence. However, as evidence maps do not permit the critical appraisal of the robustness of evidence, the evidence clusters (ie, studies) still require verification. ${ }^{19}$

\section{Evidence gaps}

Longitudinal studies were rare and the few that did observe changes in preference over time generally concerned end-of-life care preferences. ${ }^{3359636466161}$ The only intervention study we identified ${ }^{93}$ highlighted the fragility of prioritisation processes over time, and showed that health priorities shared by patients and physicians were often not sustainable 2 weeks after an intervention. Preferences tend to change when chronic conditions worsen, ${ }^{33} 59636466161$ additional diagnoses are made that lead patients to prioritise a new condition over existing ones ${ }^{30}$ or new information about treatment options is obtained. ${ }^{37}$ However, although crucial in clinical decision making, it is unclear how and why patient preferences change significantly over time. High quality longitudinal studies are needed to help physicians deal with changing preferences and to reassess preference-sensitive decisions.

We identified a further research gap in a lack of studies in older patients with multimorbidity that test the effectiveness (1) of interventions using different methods to elicit/construct preferences, and (2) of (complex) interventions that proactively consider patient preferences among patient-relevant outcomes.

The smallest cluster (containing only one study) concerned the preferences of older patients with multimorbidity with respect to screening or diagnostic tests. ${ }^{160}$ This finding is surprising, as the additional health-related burden of screening and diagnostic tests can be substantial, and it is well-known that the risk-benefit ratio of such tests can be highly preference-sensitive. ${ }^{13}$

It is worthy of note that end-of-life care preferences were mostly assessed in specialised ambulatory care. As palliative care is a core task in primary care, we would 
have expected more studies to address such end-of-life preferences in this setting. ${ }^{162}$

\section{Comparison with other studies}

This is the first evidence map of health-related preferences in older patients with multimorbidity. Although previously published evidence summaries, such as scoping or systematic reviews, partially addressed specific topics relating to some of the clusters identified in this evidence map, none focused on older patients with multimorbidity.

Four systematic reviews explored preferences in endof-life care (as well as other preferences, such as involvement in shared decision making and goal setting): (1) Puts $e t \mathrm{al}^{163164}$ systematically reviewed factors influencing older adults' (not necessarily multimorbid) decision to accept or refuse cancer treatment, (2) de Decker et $a l^{165}$ confirmed an association of the wish not to be resuscitated with multimorbidity, (3) Singh et al ${ }^{166}$ conducted a meta-analysis on the roles cancer patients (not necessarily multimorbid) prefer to play in treatment decision-making and (4) Vermunt $e t a l^{167}$ evaluated studies of the effects of interventions that support collaborative goal setting in elderly people with a chronic health condition or multimorbidity, including our only intervention study. ${ }^{93}$

Most of the evidence summaries of health-related preferences focused on end-of-life care preferences, and specifically its determinants. ${ }^{163-165}$ Further research should concentrate on the clusters and gaps identified in our evidence map in order to enhance our understanding of the preferences of older patients with multimorbidity.

\section{Strengths and limitations}

A major strength of our approach is that we used a sensitive strategy that combined controlled terms (ie, a defined vocabulary to index and retrieve information from the included electronic databases) and free-text searches in all relevant databases. Furthermore, we did not apply any restrictions to publication language, design or geographical location of the studies. Additionally, we searched for unpublished studies in registries and contacted authors of conference papers.

However, we addressed a broad topic with incomplete indexing (both, multimorbidity and patient preferences) and may have missed studies. In particular, we did not include search terms for specific measures of preference (eg, analytic hierarchy process, discrete choice experiment and conjoint analyses) in electronic searches, because test searches including them did not increase sensitivity. Furthermore, we did not search grey literature, as this approach would not have identified additional relevant studies that could have justified the enormous effort involved. ${ }^{168}$

Despite the experience gathered in the pilot study (published elsewhere), the use of a lower age limit of at least 60 years was difficult to operationalise, as studies often included a wide age range but did not always report separate results for older patients. When the age group was unclear, we did not include the study.
Furthermore, we used an iterative process to develop our evidence clusters and the identified clusters and their definitions were agreed on by all authors. However, inherent to the methods used, we cannot rule out some subjectivity.

\section{CONCLUSIONS AND FURTHER RESEARCH OUTLOOK}

This evidence map provides the first systematic overview of empirical investigations concerning health-related preferences of older patients with multimorbidity. Their objectives addressed a broad range of relevant topics across all settings and used predominantly cross-sectional and observational qualitative and quantitative methods. Our evidence map also revealed gaps, both in general such as the scarcity of longitudinal studies to investigate changes in preferences over time, and of intervention studies, which, with one exception, ${ }^{93}$ failed to develop and test interventions to support the construction of healthrelated preferences in this population. More specifically, we found a remarkably low number of studies addressing preferences concerning end-of-life care in a primary care setting, as well as preferences related to screening and diagnostic testing. Furthermore, the included studies varied considerably in terms of terminology (eg, preferences, priorities, views and perceptions) and decisionmaking components and concepts (eg, trade-offs, decision regret and goal setting). These require further elucidation.

\section{Author affiliations}

${ }^{1}$ Institute of General Practice, Johann Wolfgang Goethe-University Frankfurt am Main, Frankfurt am Main, Hessen, Germany

${ }^{2}$ Red de Investigación en Servicios de Salud en Enfermedades Crónicas, Madrid, Spain

${ }^{3}$ Institute for Evidence in Medicine (for Cochrane Germany Foundation), Medical Center, University of Freiburg Faculty of Medicine, Freiburg, Baden-Württemberg, Germany

${ }^{4}$ Institute of Medical Biometry and Statistics, University of Freiburg Faculty of Medicine, Freiburg, Baden-Württemberg, Germany

${ }^{5}$ Department of Public Health and Primary Care, Leiden University Medical Center, Leiden, Zuid-Holland, Netherlands

${ }^{6}$ Department of Family Medicine, Care and Public Health Research Institute (CAPHRI), Maastricht University, Maastricht, Limburg, Netherlands

${ }^{7}$ Patient Representative, Federal Joint Committee, Gemeinsamer Bundesausschuss,

Berlin, Germany

${ }^{8}$ Center for Adaptative Rationality, Max-Planck-Institute for Human Development, Berlin, Germany

${ }^{9}$ Institute for Evidence-Based Healthcare, Bond University Faculty of Health Sciences and Medicine, Gold Coast, Queensland, Australia

${ }^{10}$ Department of Medicine, University of Toronto, Toronto, Ontario, Canada

Acknowledgements The authors would like to thank Katharina Wollmann for her support in the literature screening process, as well as Jessica Comilang for her assistance in providing full texts of the screened studies and Pauline Philipp for her support in contacting authors of conference proceedings manuscripts.

Contributors AIG wrote the initial draft of the manuscript. CM is the guarantor of the review. CS and JJM provided methodological guidance and revisions to the manuscript. EM developed and carried out the search strategy. CS and JN assisted in the identification of databases and the search strategy. AIG and JN screened the studies, extracted the data and performed content analysis. AIG summarised descriptives, and TSN, M-SB and JN assisted with figures. JB, MvdA, TSN, M-SB, OW, KR, TH, FMG and SES are co-supervisors of this project, provided advice at all 
stages of the development of the protocol, and contributed to the revision of the manuscript. All authors read and approved the final manuscript.

Funding This work was supported by the German Federal Ministry of Education and Research, grant number 01GL1729.

Competing interests None declared.

Patient consent for publication Not required.

Provenance and peer review Not commissioned; externally peer reviewed.

Data availability statement All data relevant to the study are included in the article or uploaded as supplementary information.

Open access This is an open access article distributed in accordance with the Creative Commons Attribution Non Commercial (CC BY-NC 4.0) license, which permits others to distribute, remix, adapt, build upon this work non-commercially, and license their derivative works on different terms, provided the original work is properly cited, appropriate credit is given, any changes made indicated, and the use is non-commercial. See: http://creativecommons.org/licenses/by-nc/4.0/.

\section{ORCID iDs}

Ana Isabel Gonzalez http://orcid.org/0000-0002-1707-0596

Odette Wegwarth http://orcid.org/0000-0003-0885-2673

\section{REFERENCES}

1 van den Akker M, Buntinx F, Knottnerus JA. Comorbidity or multimorbidity: what's in a name? A review of literature. Eur J Gen Pract 1996;2:65-70.

2 Weiss CO, Varadhan R, Puhan MA, et al. Multimorbidity and evidence generation. J Gen Intern Med 2014;29:653-60.

3 Fortin M, Bravo G, Hudon C, et al. Prevalence of multimorbidity among adults seen in family practice. Ann Fam Med 2005;3:223-8.

4 Vogeli $\mathrm{C}$, Shields AE, Lee TA, et al. Multiple chronic conditions: prevalence, health consequences, and implications for quality, care management, and costs. J Gen Intern Med 2007;22:391-5.

5 N'Goran AA, Déruaz-Luyet A, Haller DM, et al. Comparing the self-perceived quality of life of multimorbid patients and the general population using the EQ-5D-3L. PLoS One 2017;12:e0188499.

6 May CR, Eton DT, Boehmer K, et al. Rethinking the patient: using burden of treatment theory to understand the changing dynamics of illness. BMC Health Serv Res 2014;14:281.

7 Sav A, King MA, Whitty JA, et al. Burden of treatment for chronic illness: a concept analysis and review of the literature. Health Expect 2015;18:312-24.

8 Zulman DM, Asch SM, Martins SB, et al. Quality of care for patients with multiple chronic conditions: the role of comorbidity interrelatedness. J Gen Intern Med 2014;29:529-37.

9 Boyd CM, Darer J, Boult C, et al. Clinical practice guidelines and quality of care for older patients with multiple comorbid diseases: implications for pay for performance. JAMA 2005;294:716-24.

10 Muth $\mathrm{C}$, Kirchner $\mathrm{H}$, van den Akker M, et al. Current guidelines poorly address multimorbidity: pilot of the interaction matrix method. J Clin Epidemiol 2014;67:1242-50.

11 Institute of Medicine. Crossing the quality chasm: a new health system for the 21 st century. Washington DC: National Academy Press, 2001.

12 Muth C, van den Akker M, Blom JW, et al. The Ariadne principles: how to handle multimorbidity in primary care consultations. BMC Med 2014:12:223.

13 Muth C, Blom JW, Smith SM, et al. Evidence supporting the best clinical management of patients with multimorbidity and polypharmacy: a systematic guideline review and expert consensus. J Intern Med 2019;285:272-88.

14 Valderas JM, Gangannagaripalli J, Nolte E, et al. Quality of care assessment for people with multimorbidity. J Intern Med 2019.

15 Lichtenstein S, Slovic P. The construction of preference. Cambridge; New York: Cambridge University Press, 2006.

16 Wegwarth O, Gigerenzer G. Statistical illiteracy in doctors. In: Gigerenzer G, Muir Gray J, eds. Better doctors, better patients, better decisions: Envisioning health care 2020 Strüngmann forum report. 1st edn. Cambridge, UK: MIT Press, 2011: 137-51.

17 Hoffmann TC, Del Mar C. Patients' expectations of the benefits and harms of treatments, screening, and tests: a systematic review. JAMA Intern Med 2015;175:274.

18 Tinetti ME, Fried TR, Boyd CM. Designing health care for the most common chronic Condition-Multimorbidity. JAMA 2012;307.
19 Miake-Lye IM, Hempel S, Shanman R, et al. What is an evidence MAP? A systematic review of published evidence maps and their definitions, methods, and products. Syst Rev 2016;5.

20 González-González Al, Schmucker C, Blom J, et al. Health-related preferences of older patients with multimorbidity: the protocol for an evidence MAP. BMJ Open 2019;9:e029724.

21 Tricco AC, Lillie E, Zarin W, et al. PRISMA extension for scoping reviews (PRISMA-ScR): checklist and explanation. Ann Intern Med 2018;169:467.

22 U.S.National Library of Medicine. ClinicalTrials.gov [Internet]. Available: http://clinicaltrials.gov/

23 World Health Organization. International Clinical Trials Registry Platform (ICTRP) [Internet]. Available: http://www.who.int/ictrp/en/

24 Holland AE, Harrison SL, Brooks D. Multimorbidity, frailty and chronic obstructive pulmonary disease. Chron Respir Dis 2016;13:372-82.

25 Chamberlain AM, St Sauver JL, Gerber Y, et al. Multimorbidity in heart failure: a community perspective. Am J Med 2015;128:38-45.

26 Fraser SDS, Taal MW. Multimorbidity in people with chronic kidney disease: implications for outcomes and treatment. Curr Opin Nephrol Hypertens 2016;25:465-72.

27 Erlingsson C, Brysiewicz P. A hands-on guide to doing content analysis. African J Emerg Med 2017;7:93-9.

28 Brunner-La Rocca H-P, Rickenbacher P, Muzzarelli S, et al. Endof-life preferences of elderly patients with chronic heart failure. Eur Heart J 2012;33:752-9.

29 Baxter K. Changing choices: disabled and chronically ill people's experiences of reconsidering choices. Chronic IIIn 2013;9:116-32.

30 Morris RL, Sanders C, Kennedy AP, et al. Shifting priorities in multimorbidity: a longitudinal qualitative study of patient's prioritization of multiple conditions. Chronic IIIn 2011;7:147-61.

31 Krucien N, Le Vaillant M, Pelletier-Fleury N. What are the patients' preferences for the chronic care model? An application to the obstructive sleep apnoea syndrome. Health Expect 2015;18:2536-48.

32 Krumholz HM, Phillips RS, Hamel MB, et al. Resuscitation preferences among patients with severe congestive heart failure. Circulation 1998;98:648-55.

33 Tang ST, Wen F-H, Hsieh C-H, et al. Preferences for life-sustaining treatments and associations with accurate prognostic awareness and depressive symptoms in terminally ill cancer patients' last year of life. J Pain Symptom Manage 2016;51:41-51.

34 Wright AA, Mack JW, Kritek PA, et al. Influence of patients preferences and treatment site on cancer patients' end-of-life care. Cancer 2010;116:4656-63.

35 Zafar SY, Malin JL, Grambow SC, et al. Chemotherapy use and patient treatment preferences in advanced colorectal cancer: a prospective cohort study. Cancer 2013;119:854-62.

36 Hamel MB, Lynn J, Teno JM, et al. Age-related differences in care preferences, treatment decisions, and clinical outcomes of seriously ill hospitalized adults: lessons from support. J Am Geriatr Soc 2000;48:S176-82.

37 Ainslie N, Beisecker AE. Changes in decisions by elderly persons based on treatment description. Arch Intern Med 1994;154:2225-33.

38 Fried TR, Tinetti ME, Towle V, et al. Effects of benefits and harms on older persons' willingness to take medication for primary cardiovascular prevention. Arch Intern Med 2011;171.

39 Caldwell PH, Arthur HM, Demers C. Preferences of patients with heart failure for prognosis communication. Can $\mathrm{J}$ Cardiol 2007;23:791-6.

40 Linsky A, Simon SR, Bokhour B. Patient perceptions of proactive medication discontinuation. Patient Educ Couns 2015;98:220-5.

41 Linsky A, Simon SR, Stolzmann K, et al. Patient perceptions of deprescribing: survey development and psychometric assessment. Med Care 2017;55:306-13.

42 McKillop G, Joy J. Patients' experience and perceptions of polypharmacy in chronic kidney disease and its impact on adherent behaviour. J Ren Care 2013;39:200-7.

43 Milic M, Foster A, Rihawi K, et al. 'Tablet burden' in patients with metastatic breast cancer. Eur J Cancer 2016;55:1-6.

44 Morrow AS, Haidet P, Skinner J, et al. Integrating diabetes selfmanagement with the health goals of older adults: a qualitative exploration. Patient Educ Couns 2008;72:418-23.

45 Noël PH, Frueh BC, Larme AC, et al. Collaborative care needs and preferences of primary care patients with multimorbidity. Health Expect 2005;8:54-63.

46 Pardon K, Deschepper R, Stichele RV, et al. Preferences of advanced lung cancer patients for patient-centred information and decision-making: a prospective multicentre study in 13 hospitals in Belgium. Patient Educ Couns 2009;77:421-9. 
47 Rifkin DE, Laws MB, Rao M, et al. Medication adherence behavior and priorities among older adults with CKD: a semistructured interview study. Am J Kidney Dis 2010;56:439-46.

48 Song M-K, Lin F-C, Gilet CA, et al. Patient perspectives on informed decision-making surrounding dialysis initiation. Nephrol Dial 2013;28:2815-23.

49 Tariman JD, Doorenbos A, Schepp KG, et al. Patient, physician and contextual factors are influential in the treatment decision making of older adults newly diagnosed with symptomatic myeloma. Cancer Treat Commun 2014:2:34-47.

50 Chiu C, Feuz MA, McMahan RD, et al. "Doctor, make my decisions": decision control preferences, advance care planning, and satisfaction with communication among diverse older adults. $J$ Pain Symptom Manage 2016;51:33-40.

51 Clover A, Browne J, McErlain P, et al. Patient approaches to clinical conversations in the palliative care setting. J Adv Nurs 2004;48:333-41.

52 Efficace F, Gaidano G, Sprangers M, et al. Preference for involvement in treatment decisions and request for prognostic information in newly diagnosed patients with higher-risk myelodysplastic syndromes. Ann Oncol 2014;25:447-54.

53 Fried TR, McGraw S, Agostini JV, et al. Views of older persons with multiple morbidities on competing outcomes and clinical decisionmaking. J Am Geriatr Soc 2008;56:1839-44.

54 Hopper I, de Silva C, Skiba M, et al. Attitudes of patients and prescribing clinicians to polypharmacy and medication withdrawal in heart failure. J Card Fail 2016;22:743-4

55 Huang ES, Gorawara-Bhat R, Chin MH. Self-reported goals of older patients with type 2 diabetes mellitus. J Am Geriatr Soc 2005;53:306-11.

56 Jones J, Nowels C, Kutner JS, et al. Shared decision making and the use of a patient decision aid in advanced serious illness: provider and patient perspectives. Health Expect 2015;18:3236-47.

57 Jorgensen ML, Young JM, Solomon MJ. Adjuvant chemotherapy for colorectal cancer: age differences in factors influencing patients treatment decisions. Patient Prefer Adherence 2013;7:827-34.

58 Fried TR, Bradley EH, Towle VR, et al. Assessment of patient preferences: integrating treatments and outcomes. The Gerontol 2002;57:S348-54.

59 Fried TR, O'Leary J, Van Ness P, et al. Inconsistency over time in the preferences of older persons with advanced illness for lifesustaining treatment. J Am Geriatr Soc 2007;55:1007-14.

60 Casarett D, Van Ness PH, O'Leary JR, et al. Are patient preferences for life-sustaining treatment really a barrier to hospice enrollment for older adults with serious illness? J Am Geriatr Soc 2006;54:472-8.

61 Cosgriff JA, Pisani M, Bradley EH, et al. The association between treatment preferences and trajectories of care at the end-of-life. $J$ Gen Intern Med 2007;22:1566-71.

62 Downey L, Au DH, Curtis JR, et al. Life-Sustaining treatment preferences: matches and mismatches between patients preferences and clinicians' perceptions. J Pain Symptom Manage 2013;46:9-19.

63 Dunlay SM, Swetz KM, Redfield MM, et al. Resuscitation preferences in community patients with heart failure. Circ Cardiovasc Qual Outcomes 2014;7:353-9.

64 Fried TR, Van Ness PH, Byers AL, et al. Changes in preferences for life-sustaining treatment among older persons with advanced illness. J Gen Intern Med 2007;22:495-501.

65 Hamel MBet al. Patient age and decisions to withhold life-sustaining treatments from seriously ill, hospitalized adults. Ann Intern Med 1999;130:116-25.

66 Janssen DJA, Spruit MA, Schols JMGA, et al. Predicting changes in preferences for life-sustaining treatment among patients with advanced chronic organ failure. Chest 2012;141:1251-9.

67 Klindtworth K, Oster P, Hager K, et al. Living with and dying from advanced heart failure: understanding the needs of older patients at the end of life. BMC Geriatr 2015;15:125.

$68 \mathrm{Li} \mathrm{W}, \mathrm{Ng} \mathrm{HL}$, Li W, et al. Treatment preferences at the end-of-life in Parkinson's disease patients. Mov Disord Clin Pract 2016;3:483-9.

69 Lynn J, Ely EW, Zhong Z, et al. Living and dying with chronic obstructive pulmonary disease. J Am Geriatr Soc 2000;48:S91-100.

70 Moss AH, Hozayen O, King K, et al. Attitudes of patients toward cardiopulmonary resuscitation in the dialysis unit. Am J Kidney Dis 2001;38:847-52.

71 O'Brien LA, Grisso JA, Maislin G, et al. Nursing home residents' preferences for life-sustaining treatments. JAMA 1995;274:1775-9.

72 Ostermann ME, Nelson SR. Haemodialysis patients' views on their resuscitation status. Nephrol Dial Transpl 2003;18:1644-7.

73 Parr JD, Zhang B, Nilsson ME, et al. The influence of age on the likelihood of receiving end-of-life care consistent with patient treatment preferences. J Palliat Med 2010;13:719-26.
74 Rahemi Z, Williams CL, Tappen RM, et al. Health-related decisions for serious illness among ethnically diverse older adults. ANS Adv Nurs Sci 2018;41:84-97.

75 Reinke LF, Slatore CG, Udris EM, et al. The association of depression and preferences for life-sustaining treatments in veterans with chronic obstructive pulmonary disease. $J$ Pain Symptom Manage 2011;41:402-11.

76 Sharma R, Jayathissa S, Weatherall M. Cardiopulmonary resuscitation knowledge and opinions on end of life decision making of older adults admitted to an acute medical service. N Z Med J 2016;129:26-36.

77 Stapleton RD, Nielsen EL, Engelberg RA, et al. Association of depression and life-sustaining treatment preferences in patients with COPD. Chest 2005;127:328-34.

78 Tang ST, Liu T-W, Wen F-H, et al. A decade of changes in preferences for life-sustaining treatments among terminally ill patients with cancer. J Natl Compr Canc Netw 2015;13:1510-8.

79 Teno JM, Fisher E, Hamel MB, et al. Decision-making and outcomes of prolonged ICU stays in seriously ill patients. J Am Geriatr Soc 2000;48:S70-4.

80 Uhlmann RF, Pearlman RA, Robert A. Perceived quality of life and preferences for life-sustaining treatment in older adults. Arch Intern Med 1991;151:495-2.

81 Weeks JC, Cook EF, O'Day SJ, et al. Relationship between cancer patients' predictions of prognosis and their treatment preferences. JAMA 1998;279:1709-11.

82 Bratzke LC, Muehrer RJ, Kehl KA, et al. Self-management priority setting and decision-making in adults with multimorbidity: a narrative review of literature. Int J Nurs Stud 2015;52:744-55.

83 Beverly EA. Incorporating comorbidity, values and preferences into clinical care guidelines designed for older adults living with type 2 diabetes. The Pennsylvania State University, 2008.

84 Cheraghi-Sohi S, Bower P, Kennedy A, et al. Patient priorities in osteoarthritis and comorbid conditions: a secondary analysis of qualitative data. Arthritis Care Res 2013;65:920-7.

85 Junius-Walker U, Stolberg D, Steinke P, et al. Health and treatment priorities of older patients and their general practitioners: a crosssectional study. Qual Prim Care 2011;19:67-76.

86 Kerr EA, Heisler M, Krein SL, et al. Beyond comorbidity counts: how do comorbidity type and severity influence diabetes patients treatment priorities and self-management? J Gen Intern Med 2007:22:1635-40

87 Lindsay S. Prioritizing illness: lessons in Self-managing multiple chronic diseases. Can J Sociol 2009;34:983-1002.

88 McDonald VM, Higgins I, Simpson JL, et al. The importance of clinical management problems in older people with COPD and asthma: do patients and physicians agree? Prim Care Respir J 2011:20:389-95.

89 Richardson LM, Hill JN, Smith BM, et al. Patient prioritization of comorbid chronic conditions in the Veteran population: implications for patient-centered care. SAGE Open Med 2016;4:205031211668094.

90 Zulman DM, Kerr EA, Hofer TP, et al. Patient-provider concordance in the prioritization of health conditions among hypertensive diabetes patients. J Gen Intern Med 2010;25:408-14.

91 Nancy ES, Corinne L, William E. "It's a toss up between my hearing, my heart, and my hip": Prioritizing and Accommodating Multiple Morbidities by Vulnerable Older Adults. J Health Care Poor Underserved 2008;20:134-51.

92 Fix GM, Cohn ES, Solomon JL, et al. The role of comorbidities in patients' hypertension self-management. Chronic IIIn 2014;10:81-92.

93 Junius-Walker U, Wrede J, Voigt I, et al. Impact of a prioritysetting consultation on doctor-patient agreement after a geriatric assessment: cluster randomised controlled trial in German general practices. Qual Prim Care 2012;20:321-34.

94 Proctor EK, Hasche L, Morrow-Howell N, et al. Perceptions about competing psychosocial problems and treatment priorities among older adults with depression. Psychiatr Serv 2008:59:670-5.

95 Beverly EA, Wray LA, Chiu CJ, et al. Perceived challenges and priorities in co-morbidity management of older patients with type 2 diabetes. Diabet Med 2011;28:781-4.

96 Bower P, Harkness E, Macdonald W, et al. Illness representations in patients with multimorbid long-term conditions: qualitative study. Psychol Health 2012;27:1211-26.

97 Cheraghi-Sohi S, Morden A, Bower P, et al. Exploring patient priorities among long-term conditions in multimorbidity: a qualitative secondary analysis. SAGE Open Med 2013;1.

98 Hansen $\mathrm{H}$, Pohontsch $\mathrm{N}$, van den Bussche $\mathrm{H}$, et al. Reasons for disagreement regarding illnesses between older patients with multimorbidity and their GPs - a qualitative study. BMC Fam Pract 2015;16. 
99 Haverhals LM, Lee CA, Siek KA, et al. Older adults with multimorbidity: medication management processes and design implications for personal health applications. J Med Internet Res 2011;13:e44-12.

100 Manias E, Claydon-Platt K, McColl GJ, et al. Managing complex medication regimens: perspectives of consumers with osteoarthritis and healthcare professionals. Ann Pharmacother 2007;41:764-71.

101 Moen J, Bohm A, Tillenius T, et al. "I don't know how many of these [medicines] are necessary." - a focus group study among elderly users of multiple medicines. Patient Educ Couns 2009;74:135-41.

102 Pagès-Puigdemont N, Mangues MA, Masip M, et al. Patients' perspective of medication adherence in chronic conditions: a qualitative study. Adv Ther 2016;33:1740-54.

103 Brown VA, Bartholomew LK, Naik AD. Management of chronic hypertension in older men: an exploration of patient goal-setting. Patient Educ Couns 2007;69:93-9.

104 Zulman DM, Jenchura EC, Cohen DM, et al. How can eHealth technology address challenges related to multimorbidity? perspectives from patients with multiple chronic conditions. J Gen Intern Med 2015;30:1063-70.

105 Rothman MD, Van Ness PH, O'Leary JR, et al. Refusal of medical and surgical interventions by older persons with advanced chronic disease. J Gen Intern Med 2007;22:982-7.

106 de Vries ST, de Vries FM, Dekker T, et al. The role of patients' age on their preferences for choosing additional blood pressurelowering drugs: a discrete choice experiment in patients with diabetes. PLoS One 2015;10:e0139755.

107 DiNapoli EA, Cinna C, Whiteman KL, et al. Mental health treatment preferences and challenges of living with multimorbidity from the veteran perspective. Int J Geriatr Psychiatry 2016;31:1097-104

108 Caughey G, Tait K, Vitry A, et al. Influence of medication risks and benefits on treatment preferences in older patients with multimorbidity. Partient Prefer Adherence 2017;11:131-40.

109 Morton RL, Snelling P, Webster AC, et al. Dialysis modality preference of patients with CKD and family caregivers: a discretechoice study. Am J Kidney Dis 2012;60:102-11.

110 Chanouzas D, Ng KP, Fallouh B, et al. What influences patient choice of treatment modality at the pre-dialysis stage? Nephrol Dial Transpl 2012;27:1542-7.

111 Morton RL, Snelling P, Webster AC, et al. Factors influencing patient choice of dialysis versus conservative care to treat end-stage kidney disease. Can Med Assoc J 2012;184:E277-83.

112 Seah AST, Tan F, Srinivas S, et al. Opting out of dialysis - Exploring patients' decisions to forego dialysis in favour of conservative nondialytic management for end-stage renal disease. Health Expect 2015:18:1018-29.

113 Visser A, Dijkstra GJ, Kuiper D, et al. Accepting or declining dialysis: considerations taken into account by elderly patients with endstage renal disease. J Nephrol 2009;22:794-9.

114 Green AR, Boyd CM, Rickard J, et al. Attitudes of older adults with serious competing health risks toward their implantable cardioverter-defibrillators: a pilot study. BMC Geriatr 2015;15:173.

115 Green AR, Jenkins A, Masoudi FA, et al. Decision-making experiences of patients with implantable cardioverter defibrillators. Pacing Clin Electrophysiol 2016;39:1061-9.

116 Parks ML, Hebert-Beirne J, Rojas M, et al. A qualitative study of factors underlying decision making for joint replacement among African Americans and Latinos with osteoarthritis. J Long Term Eff Med Implants 2014;24:205-12

117 Suggs PD, Holliday TL, Thompson SN, et al. Factors affecting choice of treatment for early-stage breast cancer in West Virginia: a 10-year experience from a rural tertiary care center. Am Surg 2017;83:709-16.

118 Gironés R, Torregrosa D, Gómez-Codina J, et al. Lung cancer chemotherapy decisions in older patients: the role of patient preference and interactions with physicians. Clin Transl Oncol 2012;14:183-9.

119 Hamelinck VC, Bastiaannet E, Pieterse AH, et al. A prospective comparison of younger and older patients' preferences for adjuvant chemotherapy and hormonal therapy in early breast cancer. Clin Breast Cancer 2016;16:379-88.

120 Puts MTE, Sattar S, McWatters K, et al. Chemotherapy treatment decision-making experiences of older adults with cancer, their family members, oncologists and family physicians: a mixed methods study. Support Care Cancer 2017;25:879-86.

121 Fox MT, Sidani S, Brooks D, et al. Perceived acceptability and preferences for low-intensity early activity interventions of older hospitalized medical patients exposed to bed rest: a cross sectional study. BMC Geriatr 2018;18:53.

122 Lyle S, Williamson E, Darton F, et al. A qualitative study of older people's experience of living with neurogenic claudication to inform the development of a physiotherapy intervention. Disabil Rehabil 2017;39:1009-17.

123 O'Dell KK, Jacelon C, Morse AN. 'I'd rather just go on as I am'-pelvic floor care preferences of frail, elderly women in residential care. Urol Nurs 2008;28:36-47.

124 Bravo RL. Medical decision-making among foreign-born Latino elders with multiple chronic conditions, 2016.

125 Chi WC, Wolff J, Greer R, et al. Multimorbidity and decision-making preferences among older adults. Ann Fam Med 2017;15:546-51.

126 Collins M, Crowley R, Karlawish JHT, et al. Are depressed patients more likely to share. J Palliat Med 2004;7:527-32.

127 Ekdahl AW, Andersson L, Friedrichsen M. "They do what they think is the best for me." Frail elderly patients' preferences for participation in their care during hospitalization. Patient Educ Couns 2010;80:233-40.

128 Ekdahl AW, Andersson L, Wiréhn A-B, et al. Are elderly people with co-morbidities involved adequately in medical decision making when hospitalised? A cross-sectional survey. BMC Geriatr 2011;11:46.

129 Moise N, Ye S, Alcántara C, et al. Depressive symptoms and decision-making preferences in patients with comorbid illnesses. $J$ Psychosom Res 2017;92:63-6.

130 Naik AD, Street RL, Castillo D, et al. Health literacy and decision making styles for complex antithrombotic therapy among older multimorbid adults. Patient Educ Couns 2011;85:499-504.

131 Perret-Guillaume C, Genet C, Herrmann FR, et al. Attitudes and approaches to decision making about antihypertensive treatment in elderly patients. J Am Med Dir Assoc 2011;12:121-8.

132 Weir K, Nickel B, Naganathan V, et al. Decision-making preferences and deprescribing: perspectives of older adults and companions about their medicines. J Gerontol B Psychol Sci Soc Sci 2018;73:e98-107

133 Belcher VN, Fried TR, Agostini JV, et al. Views of older adults on patient participation in medication-related decision making. J Gen Intern Med 2006;21:298-303.

134 Morrow DG, Weiner M, Deer MM, et al. Patient-centered Instructions for medications prescribed for the treatment of heart failure. Am J Geriatr Pharmacother 2004;2:44-52.

135 Bayliss EA, Edwards AE, Steiner JF, et al. Processes of care desired by elderly patients with multimorbidities. Fam Pract 2008;25:287-93.

136 Browne S, Macdonald S, May CR, et al. Patient, carer and professional perspectives on barriers and facilitators to quality care in advanced heart failure. PLoS One 2014;9:e93288.

137 Ehman KM, Deyo-Svendsen M, Merten Z, et al. How preferences for continuity and access differ between multimorbidity and healthy patients in a team care setting. J Prim Care Community Health 2017;8:319-23.

138 Gum AM, Iser L, Petkus A, et al. Behavioral health service utilization and preferences of older adults receiving home-based aging services. Am J Geriatr Psychiatry 2010;18:491-501.

139 Naganathan G, Kuluski K, Gill A, et al. Perceived value of support for older adults coping with multi-morbidity: patient, informal care-giver and family physician perspectives. Ageing Soc 2016;36:1891-914.

140 Pandhi N, Schumacher J, Flynn KE, et al. Patients' perceptions of safety if interpersonal continuity of care were to be disrupted. Heal Expect 2008;11:400-8.

141 Schoenborn NL, Boyd CM, McNabney M, et al. Current practices and opportunities in a resident clinic regarding the care of older adults with multimorbidity. J Am Geriatr Soc 2015;63:1645-51.

142 Utens CMA, Goossens LMA, van Schayck OCP, et al. Patient preference and satisfaction in hospital-at-home and usual hospital care for COPD exacerbations: results of a randomised controlled trial. Int J Nurs Stud 2013;50:1537-49.

143 Wieldraaijer T, Duineveld LAM, Donkervoort SC, et al. Colorectal cancer patients' preferences for type of caregiver during survivorship care. Scand J Prim Health Care 2018;36:14-19.

144 Buttery AK, Carr-White G, Martin FC, et al. Cardiac rehabilitation for heart failure: do older people want to attend and are they referred? Eur Geriatr Med 2014;5:246-51.

145 Lim CY, Berry ABL, Hirsch T, et al. Understanding what is most important to individuals with multiple chronic conditions: a qualitative study of patients' perspectives. J Gen Intern Med 2017;32:1278-84.

146 Naik AD, Martin LA, Moye J, et al. Health values and treatment goals of older, Multimorbid adults facing life-threatening illness. J Am Geriatr Soc 2016;64:625-31.

147 Robben SHM, Perry M, Olde Rikkert MGM, et al. Care-related goals of community-dwelling frail older adults. J Am Geriatr Soc 2011:59:1552-4. 
148 Schellinger SE, Anderson EW, Frazer MS, et al. Patient self-defined goals: essentials of Person-Centered care for serious illness. Am J Hosp Palliat Care 2018;35:159-65.

149 van Summeren JJ, Schuling J, Haaijer-Ruskamp FM, et al. Outcome prioritisation tool for medication review in older patients with multimorbidity: a pilot study in general practice. Br J Gen Pract 2017;67:e501-6.

150 Fried TR, Bradley EH. What matters to seriously ill older persons making end-of-life treatment decisions?: a qualitative study. J Palliat Med 2003;6:237-44.

151 Case SM, Fried TR, O'Leary J. How to ask: older adults' preferred tools in health outcome prioritization. Patient Educ Couns 2013;91:29-36.

152 Janssen IM, Gerhardus A, von Gersdorff GD, et al. Preferences of patients undergoing hemodialysis - results from a questionnairebased study with 4,518 patients. Patient Prefer Adherence 2015;9:847-55

153 Karel MJ, Mulligan EA, Walder A, et al. Valued life abilities among veteran cancer survivors. Health Expect 2016;19:679-90.

154 Tinetti ME, McAvay GJ, Fried TR, et al. Health outcome priorities among competing cardiovascular, fall injury, and medication-related symptom outcomes. J Am Geriatr Soc 2008;56:1409-16.

155 van Summeren JJGT, Haaijer-Ruskamp FM, Schuling J. Eliciting preferences of Multimorbid elderly adults in family practice using an outcome prioritization tool. J Am Geriatr Soc 2016;64:e143-8.

156 Fried TR, Tinetti ME, lannone L, et al. Health outcome prioritization as a tool for decision making among older persons with multiple chronic conditions. Arch Intern Med 2011;171:1856-6.

157 Fried TR, Tinetti M, Agostini J, et al. Health outcome prioritization to elicit preferences of older persons with multiple health conditions. Patient Educ Couns 2011;83:278-82.

158 Kuluski K, Gill A, Naganathan G, et al. A qualitative descriptive study on the alignment of care goals between older persons with multi-morbidities, their family physicians and informal caregivers. BMC Fam Pract 2013;14:133.

159 Toto PE, Skidmore ER, Terhorst L, et al. Goal attainment scaling (gas) in geriatric primary care: a feasibility study. Arch Gerontol Geriatr 2015;60:16-21.

160 Gross CP, Fried TR, Tinetti ME, et al. Decision-making and cancer screening: a qualitative study of older adults with multiple chronic conditions. J Geriatr Oncol 2015;6:93-100.

161 Fried TR, Byers AL, Gallo WT, et al. Prospective study of health status preferences and changes in preferences over time in older adults. Arch Intern Med 2006;166:890-5.

162 World Health Organization. Why palliative care is an essential function of primary health care [Internet], 2018. Available: https:// www.who.int/docs/default-source/primary-health-care-conference/ palliative.pdf?sfvrsn=ecab9b11_2

163 Puts MTE, Tapscott B, Fitch M, et al. A systematic review of factors influencing older adults' decision to accept or decline cancer treatment. Cancer Treat Rev 2015;41:197-215.

164 Puts MT, Tapscott B, Fitch M, et al. A systematic review of factors influencing older adults' hypothetical treatment decisions. Oncol Hematol Rev 2015;11:19-33.

165 de Decker L, Annweiler C, Launay C, et al. Do not resuscitate orders and aging: impact of multimorbidity on the decision-making process. J Nutr Health Aging 2014;18:330-5.
166 Singh JA, Sloan JA, Atherton PJ, et al. Preferred roles in treatment decision making among patients with cancer: a pooled analysis of studies using the control preferences scale. Am J Manag Care 2010;16:688-96.

167 Vermunt NPCA, Harmsen M, Westert GP, et al. Collaborative goal setting with elderly patients with chronic disease or multimorbidity: a systematic review. BMC Geriatr 2017;17:167.

168 Benzies KM, Premji S, Hayden KA, et al. State-of-the-evidence reviews: advantages and challenges of including grey literature. Worldviews Evid Based Nurs 2006;3:55-61.

169 Fried TR, Bradley EH, Towle VR, et al. Understanding the treatment preferences of seriously ill patients. N Engl J Med 2002;346:1061-6.

170 Davison SN. End-Of-Life care preferences and needs: perceptions of patients with chronic kidney disease. Clin J Am Soc Nephrol 2010:5:195-204.

171 Elie D, Marino A, Torres-Platas SG, et al. End-Of-Life care preferences in patients with severe and persistent mental illness and chronic medical conditions: a comparative cross-sectional study. Am J Geriatr Psychiatry 2018;26:89-97.

172 Etkind SN, Bristowe K, Bailey K, et al. How does uncertainty shape patient experience in advanced illness? a secondary analysis of qualitative data. Palliat Med 2017;31:171-80.

173 Fried TR, Gillick MR. Medical decision-making in the last six months of life: choices about limitation of care. J Am Geriatr Soc 1994;42:303-7.

174 Janssen DJA, Curtis JR, Au DH, et al. Patient-clinician communication about end-of-life care for Dutch and US patients with COPD. Eur Respir J 2011;38:268-76.

175 Janssen DJA, Spruit MA, Schols JMGA, et al. Insight into advance care planning for patients on dialysis. J Pain Symptom Manage 2013;45:104-13.

176 JSW L, LCW L, Tang CSH, et al. Attitudes of demented and nondemented Chinese elderly subjects towards end-of-life decision making. Hong Kong J Psychiatry 2006;16:45-9.

177 Maida V, Peck J, Ennis M, et al. Preferences for active and aggressive intervention among patients with advanced cancer. BMC Cancer 2010;10:592.

178 McPherson CJ, Hadjistavropoulos T, Devereaux A, et al. A qualitative investigation of the roles and perspectives of older patients with advanced cancer and their family caregivers in managing pain in the home. BMC Palliat Care 2014;13:39.

179 Piamjariyakul U, Myers S, Werkowitch M, et al. End-of-life preferences and presence of advance directives among ethnic populations with severe chronic cardiovascular illnesses. Eur $J$ Cardiovasc Nurs 2014;13:185-9.

180 Sudore RL, Schillinger D, Knight SJ, et al. Uncertainty about advance care planning treatment preferences among diverse older adults. J Health Commun 2010;15 Suppl 2:159-71.

181 Tamura MK, Goldstein MK, Perez-Stable EJ. Preferences for dialysis withdrawal and engagement in advance care planning within a diverse sample of dialysis patients. Nephrol Dial Transp I 2010;25:237-42.

182 Strachan PH, Carroll SL, de Laat S, et al. Patients' perspectives on end-of-life issues and implantable cardioverter defibrillators. $J$ Palliat Care 2011;27:6-11.

183 Adams R, May H, Swift L, et al. Do older patients find multicompartment medication devices easy to use and which are the easiest? Age Ageing 2013;42:715-20. 